\title{
Building Strong, Interdependent Relationships between People with FASD and their Supporters
}

\author{
Debbie Michaud* \\ Children's Services Supervisor, Sioux Lookout, Canada
}

Submission: December 04, 2018; Published: January 11, 2019

*Corresponding author: Debbie Michaud, Children's Services Supervisor, 9 Cedar Point Drive, Sioux Lookout, ON, P8T 0A, Canada

\begin{abstract}
Parents often feel guilty or judged when their child does not experience outcomes that they had been expecting. This can be compounded by approaches that do not appreciate the unique needs of the individual with FASD. We will explore supportive interventions which include insulation, interdependence and relationship building. The idea of "insulation" is a way to explain parenting that appears overbearing, medalling and intrusive. Sometimes young people with FASD need to be guided away from toxic or even dangerous relationships and social opportunities need to be choreographed by the caregivers or the community to ensure pro social connections. This is an effective strategy to get ahead of high-risk behavior. We will discuss the need to help individuals transitioning to adulthood to live "interdependently" so that they can rely on their families and support systems when they need an "external brain or executive assistant", and they do not feel like failures when they are unable to live "independently". We will explore systems and approaches that undermine the idea of "interdependence" and how we can do things differently. Young people living with FASD will need strong relationships with their caregivers, families and support people for a lifetime, and nurturing and developing these pre-existing relationships should be at the forefront of any intervention.
\end{abstract}

\section{Introduction}

Fetal Alcohol Spectrum Disorder (FASD) may be associated with a variety of challenges including developmental disabilities, hyperactivity, attention and impulse control problems, language delays, and social skills deficits. These problems can lead to "secondary disabilities" such as mental health issues, academic and vocational failure, substance abuse, and interactions with the justice system, Doris (1989) [1-4]. Due to the disabilities invisible nature, parenting can be challenging. Parents can find themselves struggling with the overwhelming demands of supporting children and not really knowing the cause of their child's behavior, Doris (1989) [1,2]. Their burden can be compounded as they try to navigate systems that misunderstand the disability and increase the stress $[5,6]$. We often view "bad parenting" as the cause of behavior and approaches with this philosophy can work to undermine commitment, effective parenting and compound stress for caregiver [1].

People with FASD are born with brain damage and may not always behave in ways that others expect them to. This brain damage can permeate even the best of environments to cause behavior problems and create serious parenting challenges [4]. Parents need support, not criticism [7]. Brown et al. [5] conducted a study with foster parents caring for children with FASD. They wanted to know what foster parents would need to be successful with these children. Foster parents described the need for social support, material support, a structured home environment, professionals, other foster parents, an understanding of FASD, the right kind of personality and organizational skills. They repeatedly mentioned the need for responsive professionals to deal with, and the need for these professionals to work together and treat them with respect. They discussed feeling like "clients" within the child welfare organizations and suggested that assessments of their work with children be "strengths based" in order to build on the good work they do This resonated with a theme found in Picture This: Life as a parent of children with FASD participant Bonnie [8] writes,

The Fire Pit: As a caregiver for children for FASD children, I learned that just because you provide all the "tools"' necessary to accomplish a task, doesn't mean it's going to turn out the way you expected. You may have wanted fire and brought all the necessary fuel, but only got smoke. I want society to acknowledge the work that went into making the smoke [8].

Supportive interventions which include appreciating and supporting the need for insulation, interdependence and relationships can help caregivers continue to support their children with FASD even when thing become difficult. A strengths-based approach with the underlying view that families know what is best for their children is the most effective response.

\section{Insulation}

Insulation in term of caring for children with FASD can be defined as putting into place relationships, activities, structures and routines that prevent the young person from engaging in relationships or activities that might increase risks of secondary disabilities. Insulation techniques seem to be more affective when 


\section{Global Journal of Intellectual \& Developmental Disabilities}

they are put in place with younger children, when they are done in the context of a caring relationship and then the younger person is involved in the decision making. Some insulation techniques could include:

\section{i. Constant supervision}

ii. Limited screen and internet time (supervised)

iii. Attendance at private or smaller schools with more supervision (homeschooling)

iv. Engagement in youth groups or church activities

v. Enrollment in sports or other structured activities

vi. Planned and supervised social activities in the home on a regular basis

vii. Reinforcing relationships and planning activities with pro social peers

viii. Residing in the county to prevent access to unstructured time at malls or downtown areas

ix. Developing close relationships with other families trying to create insulated environments

x. Reducing access to money outside of a supervised environment and encouraging planned spending

We can often judge insulation techniques as overbearing, medalling and intrusive. Very often parents are using the "insulation" techniques with their children in order to distract them or to get ahead of potentially dangerous situations. Sometimes young people with FASD need to be guided away from toxic or even dangerous relationships and social opportunities need to be choreographed by the caregivers or the community to ensure pro social connections. These techniques even for young adults can be very helpful in steering young people in the right directions should supported, respected and reinforced.

\section{Interdependence}

The concept of interdependence is one in which the caregivers and the child grow to rely on one another. There is a mutual dependence that develops in which both learn to value the things in which they can count on the other for. There is a real need for us to understand that young adults with FASD many need to live "interdependently" so that they can rely on their families and support systems when they need an "external brain or executive assistant (because they have their own brain)", and they do not feel like failures when they are unable to live "independently". Some approaches work to undermine young people with FASD developing and building interdependence. The idea of independence is embedded in the child welfare system, education system, mental health system and justice system.

Some ways to create interdependence:

i. Normalize the need for young people to rely on family and caregivers for their day to day decisions ii. Preparing young people to live at home longer, forever if need be

iii. Encouraging young people to share bank accounts with caregivers or have a trustee

iv. Reinforcing the need for caregivers to work with teacher and employers on decisions that affect their child

v. Holding off on full drivers licence until later in adulthood - but drive together

vi. Arranging for the young person to live with family if they need to go away for college or going with them

vii. Go with or hiring other adults to accompany young people on trips or vacations

viii. Make sure young people have strong roles in their family

ix. Having caregivers rely on young people to take care of household chores or other things that need to get done (shopping, errands, cooking)

x. Encouraging young people to contribute financially to the household

It is important that young people with FASD are supported and have help to make decisions and navigate life in a safe way with people they trust. Family and caregivers are important because paid staff allotments can change throughout the lifecycle. Young people need to know that that they are not failing in some way if they are not going off on their own and making their own decisions. By creating interdependent relationships young people can feel like a valued member of their family and community and will welcome and accept help when it is presented as a way of life and built into the fabric of family and community [9].

\section{Strong Relationships}

Care and concern for the young person could be appearing to be controlling, therefore all strategies to build interdependence and create insulation need to be used with care. We do not want for force young people out of safe relationships with caregivers into relationship that might cause risks. Ways you can nurture ongoing relationships through transitions:

\section{Caregivers}

i. Approach issues with the young person in a nonjudgmental and supportive way

ii. Do not yell or threaten the young person in anyway

iii. Do not approach things punitively - this is very important as they get older

iv. Allow for decisions and freedom as much as possible and in safe ways

v. Allow for young people to make mistakes and be supportive when they do

vi. Don't constantly remind them of their failures or what they cannot do 
vii. Allow then to make mistakes and keep taking them back

viii. Focus on what they are great at and build their confidence within the home

ix. Ensure the home environment is organized and structured with little stress

x. Have fun

xi. Smile at them, hug them, make them feel valued.

\section{Professionals}

i. Talk positively about the young person and their relationship with their caregivers

ii. Help the young person talk about and remember the good things in their relationship

iii. Encourage the young person to seek support from their caregiver

iv. Include caregivers in all decision making

v. Value the opinions of caregivers (they know the young person best)

Young people living with FASD will need strong relationships with their caregivers, families and support people for a lifetime and nurturing and developing these pre-existing relationships should be at the forefront of any intervention. Young people need to feel they belong and that they are respected [10]. When they feel safe and are welcome home unconditionally will return home. Home is where they are safest.

This work is licensed under Creative Commons Attribution 4.0 License DOI: 10.19080/GJIDD.2019.05.555673

\section{References}

1. Buxton Bonnie (2004) Damaged Angels. Alfred A. Knopf of Canada.

2. Malbin D (2007) Fetal Alcohol Spectrum Disorder; A collection of information for parents and professionals. ( $2^{\text {nd }}$ edn) FASCETS, Inc.

3. Michaud M, Michaud S (2003) Beautiful Smiles, Gentle Spirits. Detseilig Enterprises Ltd.

4. Streissguth A, Barr H, Kogan J, Bookstein F (1996) Understanding the occurrence of secondary disabilities in clients with fetal alcohol syndrome (FAS) and fetal alcohol effect (FAE). Final Report. Centre for Disease Control and Preventions.

5. Brown J, Sigvaldason N, Bednar L (2005) Foster parent perceptions of placement needs for children with a fetal alcohol spectrum disorder. Children and Youth Services Review 27(3): 309-327

6. Green S (2007) "We're tired, not sad": Benefits and burdens of mothering a child with a disability. Soc Sci Med 64(1): 150-163.

7. Graefe S (2004) Living with FASD: A guide for parents. Groundwork Press, Vancouver, Canada.

8. Lauer K (2007) “See” what I mean? A Critical Examination of Photovoice as a Participatory Action Research Strategy. Unpublished master's dissertation. Queen Margaret University, Edinburgh, Scotland.

9. Michaud D (2010) Building Bridges: Understanding the experiences of the mothers who created "Picture" This: Life as a parent of children with FASD. Unpublished Master's Thesis. Laurentian University, Sudbury, Ontario, USA.

10. Michaud D, Temple, Valarie (2013) The Complexities of Caring for Individuals with Fetal Alcohol Spectrum Disorder: The Perspective of Mothers 19: 94-101

\section{Your next submission with Juniper Publishers will reach you the below assets}

- Quality Editorial service

- Swift Peer Review

- Reprints availability

- E-prints Service

- Manuscript Podcast for convenient understanding

- Global attainment for your research

- Manuscript accessibility in different formats

( Pdf, E-pub, Full Text, Audio)

- Unceasing customer service

Track the below URL for one-step submission https://juniperpublishers.com/online-submission.php 